\title{
مشاكل ومعوقات تسويق طيور الزينة بولاية الخرطوم (محافظة أم درمان - بحري)
}

\section{مناهل التجاني حسن عكاشة}

كلية علوم وتكنولوجيا الانتاج الديواني - جامعة السودان للعلوم والتكنولوجيا

E.mail: ManahilEltigani@hotmail.com - Tel:-., Y NoN11.1

\section{ABSTRACT}

Received at: 19/5/2014

Accepted: 2/8/2014
أجريت الدراسة عام ب ا ـ rم على مشاكل ومعوقات تسويق طيور الزينة في ولاية الخرطوم بالتركيز علي

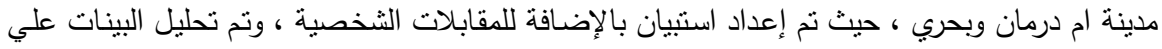

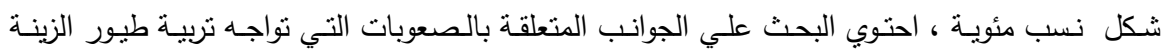
ورعايتها ومناكل تسويقها في السودان. من خلال نتائج الدراسة وجد أن طيور الزينة من الناحية الاقتصاية التهاية

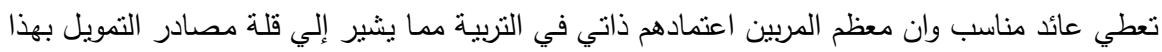
المجال ومن خلال الدراسة وجد أن مشاكل ومعوقات التسويق تتثنل في عدم الخبرة الكافية والدراية العميقة

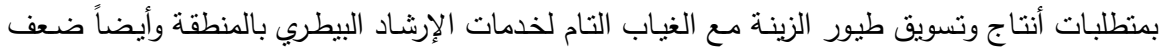
إقبال المشترين لنقافتهم الضعيفة بطيور الزينة تجعهم يعتبرونها من الكماليات.

\section{INTRODUCTION \\ المقدمـة}

طيور الزينة هي كائنات رقيقة جميلة المنظر عذبة الصوت مغردة محببة الي النفوس يعثقها الصغار والكبار لذلك فهي تربي في المنازل والفنادق والمحلات التجارية وذلك بما تضفيه علي المكان من جمال وبهاء.

تنترج طيور الزينة تحت رتبة العصفوريات وهي توجد في جميع بقاع الكرة الأرضية ، حيث تشمل ثناثة ارباع الطيور في العالم ، ومن العسير أداء هذه الكثرة الرهيبة أن يتم حصر طيور الزينة إلا أن طيور الزينة تتميز بمناقير متوسط الطول والغذة الزيتية عارية من الريش ( (1). وهذه الطيور أرضية ذات حساسية مرهفة لذلك فهي وجلة تثار لأقل حركة وأنها ضعيفة رقيقة لا تملك سلاحاً تدافع به عن نفسها وسلاحها الوحيد هو سرعة الطيران والهرب من مواطن الخطر ومسكنها المفضل الحدائق بما تحنويه من أثجار وخضرة وهي طيور مرحة زكية مستأنسة. لذلك فقد سارع المستثمرون إلي تربية هذه الطيور والإكثار منها واتخذوها تجارة رابحة لتكالب الناس علي اقتتائها لإدخال البهجة والراحة إلي نفوسهم علاوة علي تزيين المكان. ذكر علماء علم النفس بان اقتتاء وتربية العصافير مطلوبة ومستحبة فهي نوع من تخفيف حدة التوتر والقلق الإن

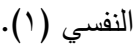

وان بعض حالات الاضطرابات النفسية كمنل الميل إلي العزلة وإضرابات السلوك بحث المرض بتربية طيور الكنار في منازلهم ، كما أن جمال طيور الزينة ورقتها ورخامة صوتها يرقان الثعور ويدخلان السرور في النفوس ((). لهذا اهتم البحث علي كيفية الاستفادة من تسويق طيور الزينة ومنتجاتها الأغراض التزبوية والعمية والتجارية والاقتصادية وذلك للأجل مساهتها في رفع المستوي المعيشي والمساهمة في الدخل القومي. ومن هذا المنطلق جاءت مشكلة البحث في الصعوبات التي تواجه تسويق طيور الزينة

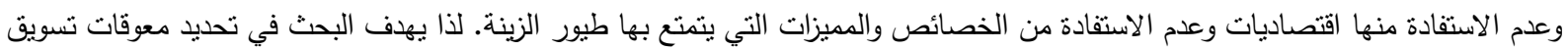
طيور الزينة وكيفية تحليل وتثخيص المشاكل التي تعوق تسويق طيور الزينة. اجري هذا البحث علي منتجي طيور الزينة في ولاية الخرطوم منطقة

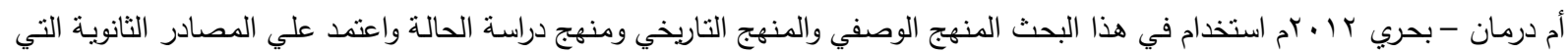
تمثلت في الكتب والتقارير والمصادر الأولية هي المقابلات الثخصية مع منتجي طيور الزينة عن طريق الاستبيان. 
الجهل بطرق التربية والرعاية وعدم التمرس علي عمليات التوليف والتزاوج وكيفية التعرف علي برامج الرعاية التناسلية وخاصة وإنها تمثل أهم العناصر اللازمة لنجاح التربية. r. بقص المعلومات عن حياة الطيور : مثال لهذه المعلومات عاداتها وتفريخها وحضانتها وأغذيتها وغيرها من المعاملات الفنية المختلفة الني تعتمد علي أسس علمية يجب الحصول عليها

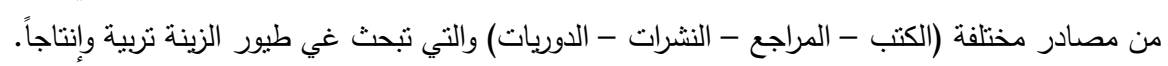

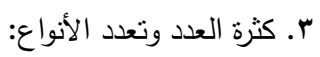

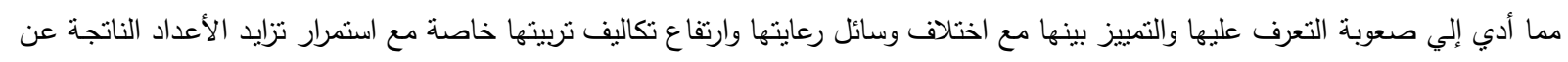
سرعة التكاثر مما يدفع بالكثير من المربين إلي الإحجام عن تربيتها والتخلص منها أو إهمالها مما يؤدي إلي فنشلها.

؛. عدم الوعي باهميتها وقيمتها:

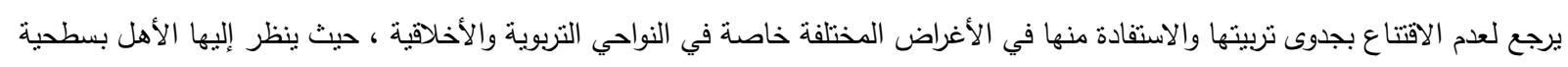

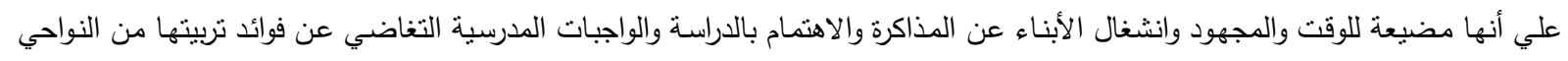
النفسية والمهنية والمشجعة للاستخكار. ه. عدم توفر الإمكانيات والمستلزمات:

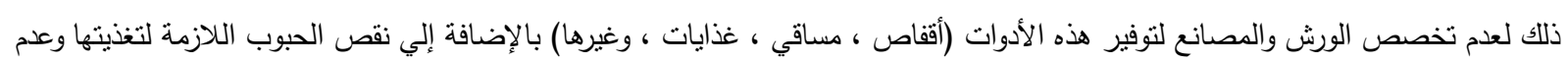
الإقبال علي زراعتها ونقص انتشارها مما يؤدي إلي نقص كميتها وارتفاع أسعارها (r).

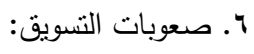
ذلك لنقص الإقبال علي اقتتائها وتربيتها لنقص الوعي علي أهيتها في نتمية الأطفال من النواحي الصحية والعلمية والنفسية وعدم الافتتاع بدورها في تحقيق عائد اقتصادي مجزي نتيجة استثمار الأموال في أنشطتها المختلفة (؟).

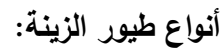

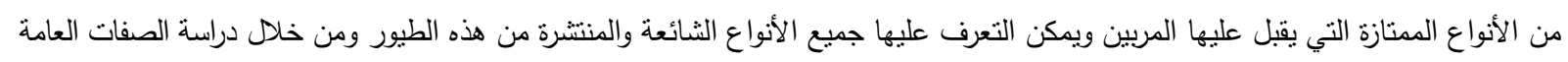

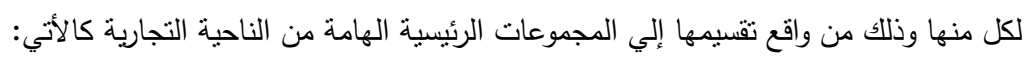
اولاً: مجموعة العصافير : العبر أتنمي هذه المجموعة إلي عدد كبير من الفصائل وعليه تتعدد سلالاتها وتشتمل علي أعداد كبيرة ومتتوعة تصل في جملتها إلي ستمائة نوع نوضح البرنس - التنرج - الاسترالي - الفردوس - زيرا - الدنكة - البركديلو - الرد سول. ثانياً: مجموعة البلابل: منها سلالات متعددة تصل عددها إلي أربعمائة سلالة وتمثاز غالبيتها بان المنقار قصير وغليظ ريشها متعدد الألوان كما جناحها قوب وطويل ومنها: الدج - الفيثاوي - دوربي - ستلا - كاردينال - شيكاري - كاونج - هومنج.

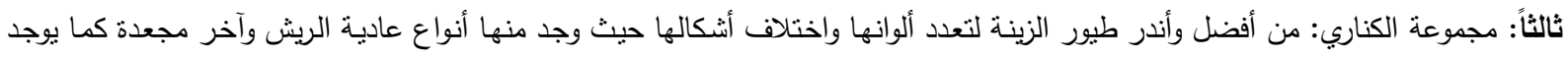

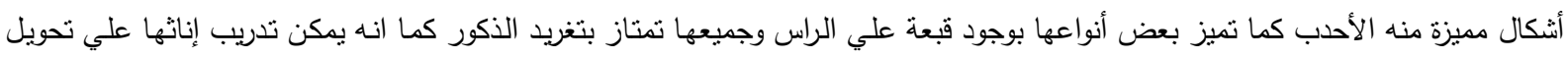

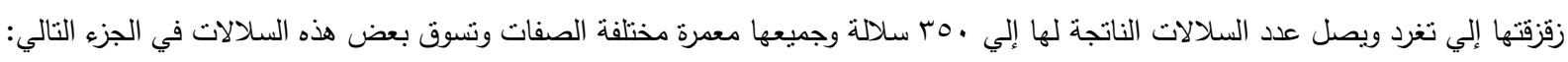
التجاري - بوردر - لانكشير - سينامون - الغرل - الرولر - اللوكستر - باستلي - بوكثير - نوفيتش - الهاروز - اينو - اسكونش.

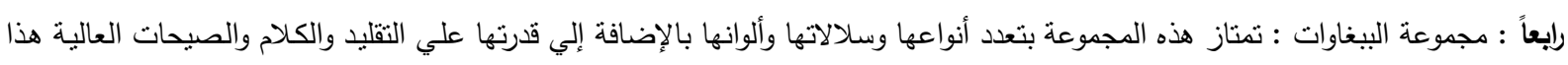

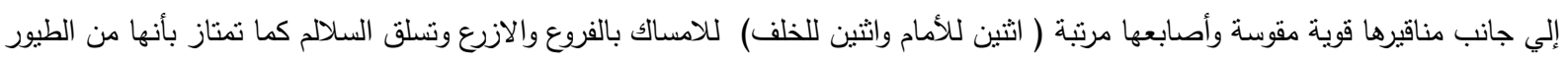

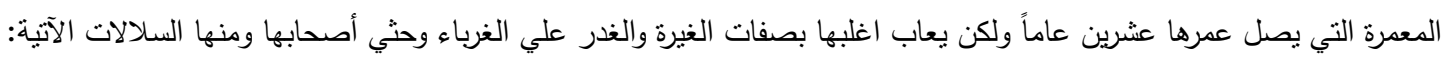


الامازون - الكوينو - الزنجاري - يجريز - مكاو - الكوكتيل - براكيت - امريكاني - كوكانو - الروكر (؟).

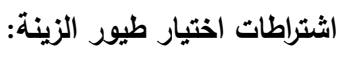
يشترط في طيور الزينة عند اختيارها لتعمير المزرعة مجموعة من الانتراطات منها: - جودة النمو وعدم الضعف. - السلامة والخلو من الأمراض حيث تندو عليها علامات الصحة الحيوية. - الخلو من العيوب الجسمية والخلقية والإصابات. - أن تكون منقاربة في العمر ويفضل ذات العمر الواحد والات ومتماتلة الحجم. - حديثة التربية ولا يزيد عمرها عن موسم واحد (الأمهات).

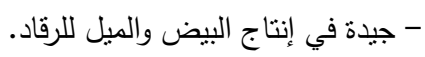

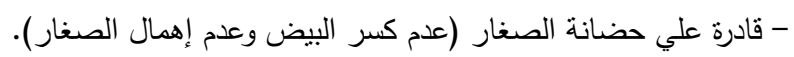

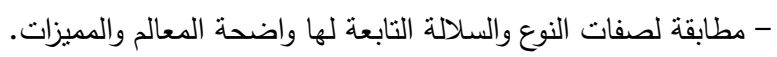

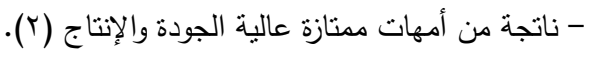

تغذية طيور الزينة:

من الاحتياجات الغذائية المهمة لطيور الزينة:

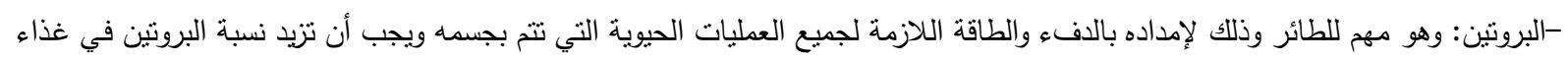
الصغار. - المواد الكربوهيدريتية: وهي هامة للجسم لإمداده بالطاقة ويجب الأتقل نسبتها في الغذاء وان تتنوع مصادرها من حبوب وثمار وفاكهة ونبات خضراء وان تكون سهلة الهضم.

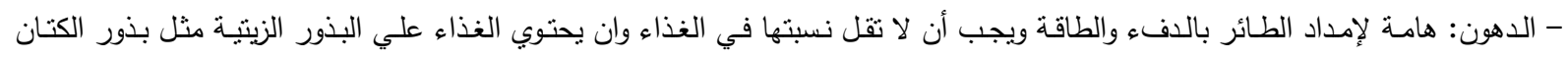

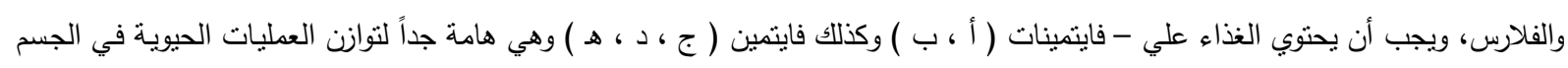

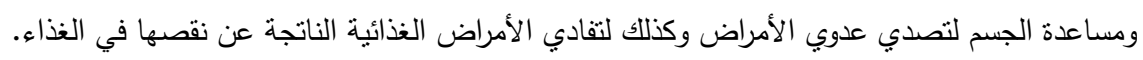

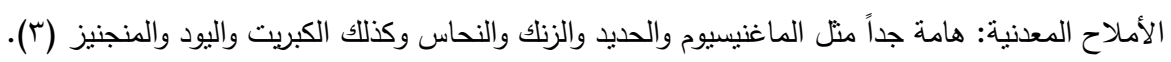
أمراض طيور الزينة والوقاية منها: الوقاية من الأمراض: لإتباع برنامج الوقاية من الأمراض ضداضد طئن طيور الزينة يجب مراعاة الأتي:

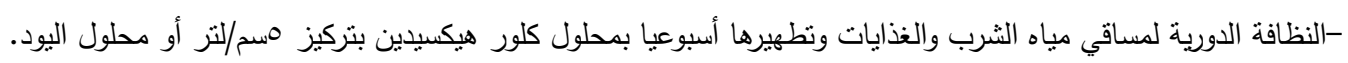

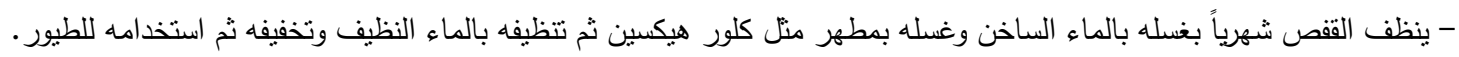
- أعثاش البيض تتظف وتغسل وتطهر بعد كل فقسه.

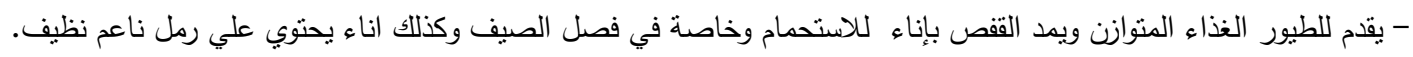

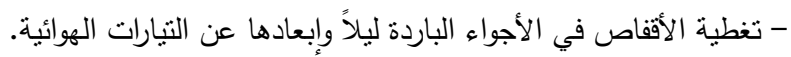

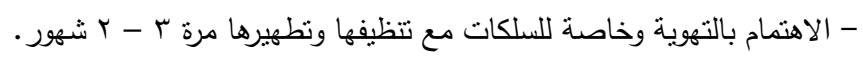

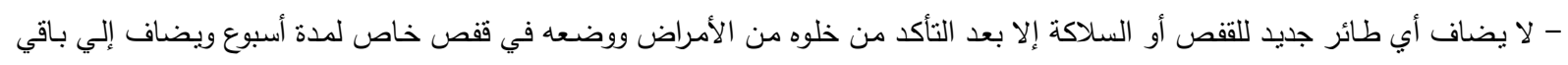
الطيور في حاله عدم ظهور أي أعراض مرضية عليه.

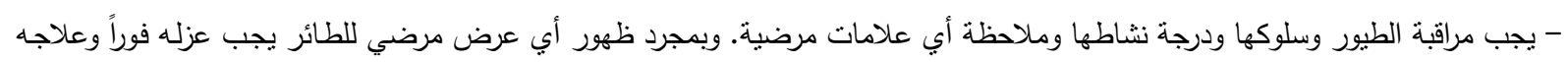

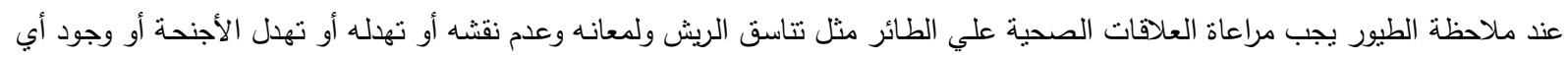

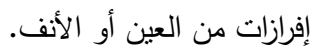
- ملاحظة العطس أو النقيؤ وكذلك زرق الطيور ولونه أو أي نوع من الإسهال.

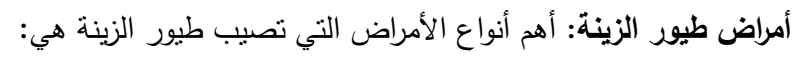

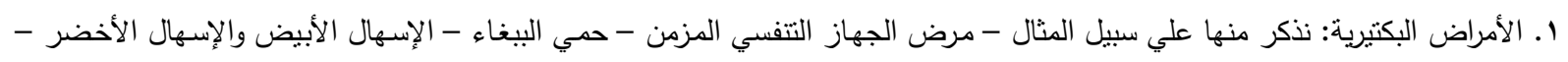
عدوي الباسترلا - السل الكاذب. r. الأمراض الفيروسية: الجدري - النيوكاسل. 
r. الطفيليات الخارجية: القراد اللين - وطفيل الجرب - القمل. ع. الطفيليات الداخلية: الجهاز الهضمي - طفيليات الجهاز التنفسي - انتفاخ العين والتهابها.

النواحي الاقتصادية لتربية طيور الزينة: هنالك العديد من المنطلبات الاقتصادية التي يجب توفرها عند تربية طيور الزينة. ا ـ تربية الأنواع المختلفة منها والاتجار منها وصغارها. r. إقامة صناعات مرافقة (أقفاص - غذايات - مساقي - علائق - أخري). r. الاستثمار وتحقيق عائد اقتصادي مجزي. ع. سرعة دوران رأس المال في تربيتها وإنشاء مزارعها. هـ اقتصادية تربيتها وذلك للأسباب النالية:

- قلة المجهود في خدمتها ورعايتها والعناية بها . - قلة رأس المال المستشر في إنثاء مزارعها أو تربيتها وقلة تكاليفها. - قلة نفقات رعاية الإباء لصغارها. - لا يتبع بها تفريخ صناعي أو حضانة صناعية. - قلة الوفيات وانتنار الأمراض (النظافة الفطربة وعدم النزاحم). -تعدد منتجاتها وارتفاع قيمتها (طيور حية - ريش - سماد). - الاستفادة بالمنتجات العرضية مثل: * الريش: (الملابس والقبعات والمراوح) * السماد والزرق: سماد عضوي غني بـالازوت يفيد في تسميد البساتين والخضر والفاكهة والزينة حيث تعطي الواحدة ما يقارب من 1.0 ــ 1.0

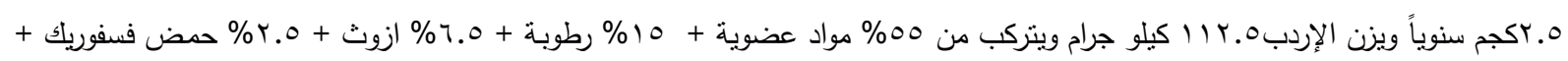
r بو باسيوم. كما يستفاد من الطيور النافقة في التحنيط والبيع لنزبين الأركان والديكورات . • معمرة لفترات طويلة تصل إلي • (1 - 10 سنة لذا فتكون حياتها الإنتاجية طويلة (r).

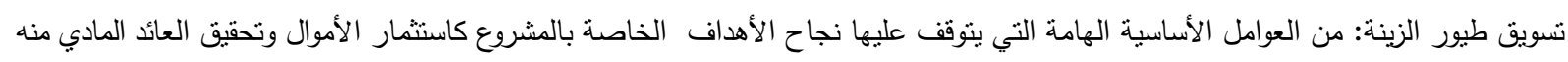
وبينلزم نجاح خطة التسويق الالتزام بتحقيق الأسس الآتية:

- دراسة الأسواق وإمكان التصريف وذلك بالاتفاق مع محلات الطيور ومستلزماتها مع وضع عوامل تشجيع زيادة المبيعات (خفض الأسعار تتوع

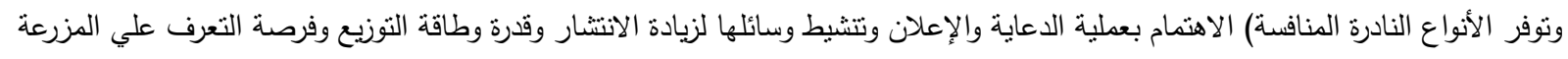

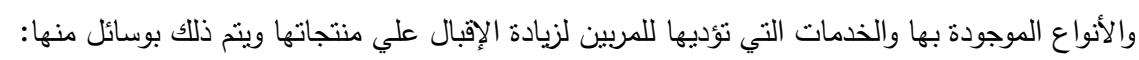

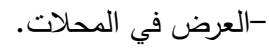

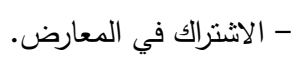

$$
\begin{aligned}
& \text { - توزيع الهدايا. } \\
& \text { - نوزيع الإعلانات وعرضها في الأماكن الظاهرة. } \\
& \text { - الإعلان في وسائل الإعلام المختلفة. }
\end{aligned}
$$

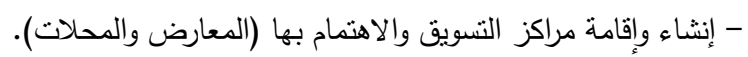

- زيادة توزيع الطيور ومستلزماتها في محلات وتجهيزها بوسائل العرض المختلفة والمناسبة مع الترغيب وحسن معاملة الهواة وعدم الغش وتوفر لهات عوامل الثقة.

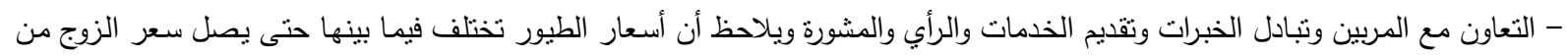

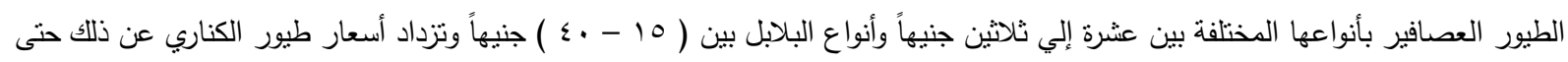

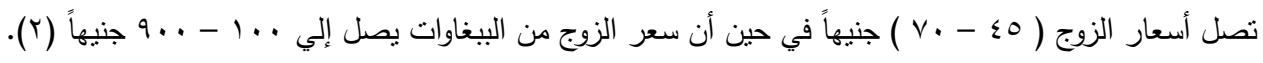


مدينة امدرمان العاصمة الوطنية يوجد بها العديد من الأسواق بداية بسوقها الكبير مروراً بأسواقها الفرعية التي تكونت بسبب ترامي أطراف المدينة

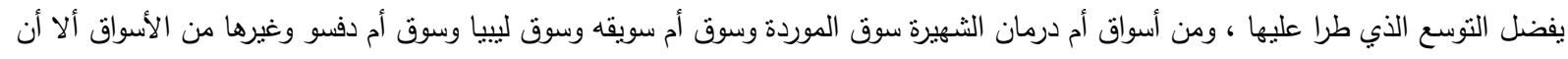

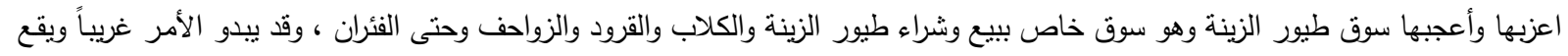
سوق الطيور علي الجانب الشرقي من سوق الدجاج والسمك (داخل سوق أم درمان الكبير) ويتكون من مجموعة أقفاص صممت بشكل هندسي كبير لتعرض عليها الحمام وطيور الزينة المجلوبة من خارج البلاد.

وان خبرة تجار سوق طيور الزينة قد اكتسبوه من أوائل التجار الذين عملوا في تجارة طيور الزينة التي كانوا يجلبونها من مصر وأبو ظبي وسوريا ويبيعونها بموقعهم بسوق الدجاج قبل أنشاء هذا السوق بالقرب من محافظة ام درمان. وقد أنشاء السوق وفق خرة خرطه هندسية ليكون سوقاً نموذجياً

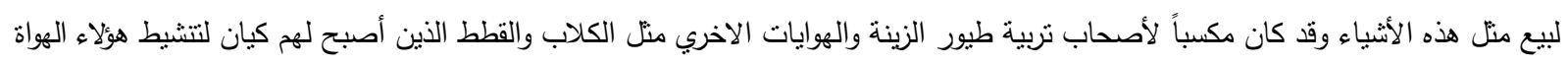
والهوايات الأخرى.

أما الموطن الأصلي لطيور الزينة هو قارة استراليا وقد سبقنا الإخوة في مصر وسوريا في هذا المجال منهم متخصصون في نربيتها وتكاثرها ويجلبونها من مواطنها الأم ونحن نستورد منهم.

أنواع طيور الزينة كثيرة وهي تزيد علي الثلاثمائة نوع إلا أن المعروف منها في السودان ( الدركدلو - ابو قمبور - الزولا - الخداري - الكناري -

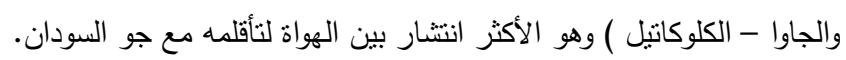

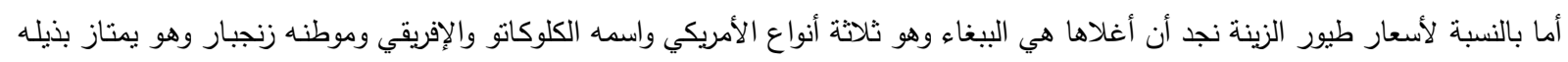
الأحمر والأمريكي يأني من مصر وهو الاغلي أما الأفريقي فهو الازكي رغم أن كل أنواع البيغاوات ناطقة وبسعر الأمريكي نسبة لامتيازه بلونه

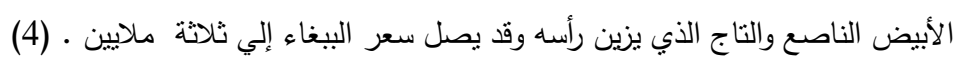

\section{ANALYSIS and DISCUSSION}

التحليل والمناقثة

جدول ا: مستوي التعليم لبائعي طيور الزينة.

\begin{tabular}{|c|c|c|}
\hline النسبة \% & العدد & مستوي التعليم \\
\hline T.ro & 1 & أمي \\
\hline 1 T.o & $r$ & أساس \\
\hline M. To & 0 & ثانوي \\
\hline 0. & $\wedge$ & جامعي \\
\hline$\% 1 \ldots$ & 17 & المجموع \\
\hline
\end{tabular}

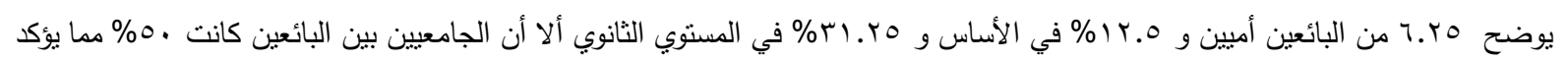
ارتفاع مستوي الوعي في تحسين وتطور أساليب وطرق تسويق طيور الزينة في السودان. الجدول r أنواع طيور الزينة التي تباع في الأسواق.

\begin{tabular}{|c|c|c|}
\hline النسبة \% & العدد & النوع الذي يباع \\
\hline Tr.o & 1 & عصافير \\
\hline T.YO & 1 & بلابل \\
\hline r..ro & 0 & ببغاء \\
\hline- & . & الكناري \\
\hline$\% 1 \ldots$ & & المجموع \\
\hline
\end{tabular}


Assiut Vet. Med. J. Vol. 60 No. 142 July 2014

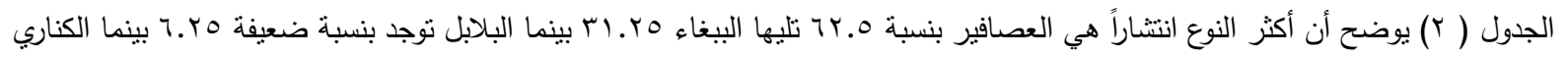
لا تتوفر إلا بالطلب نسبة لارتفاع أسعارها وصعوبة تربيتها.

الجدول r: مصدر الحصول علي طيور الزينة.

\begin{tabular}{|c|c|c|}
\hline النسبة \% & العدد & المصدر \\
\hline 0. & $\wedge$ & مزرعتلك \\
\hline M. ro & 0 & مزارع تجارية \\
\hline 11.20 & $r$ & أفراد \\
\hline$\% 1 \ldots$ & 17 & المجموع \\
\hline
\end{tabular}

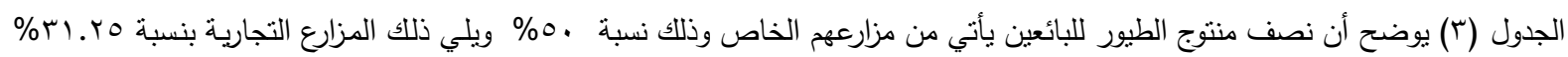

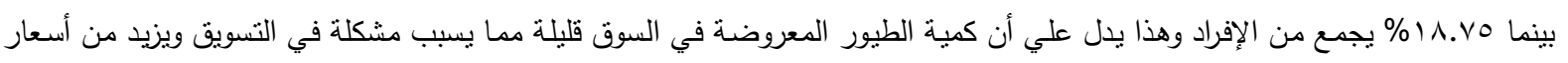
الطيور الجدول ؟ : مستوي الخبرة في تربية طيور الزينة.

\begin{tabular}{|c|c|c|}
\hline النسبة \% & العدد & توجد خبرة \\
\hline qr.vo & 10 & نعم \\
\hline T.Yo & 1 & $y$ \\
\hline$\% 1 \ldots$ & 17 & المجموع \\
\hline
\end{tabular}

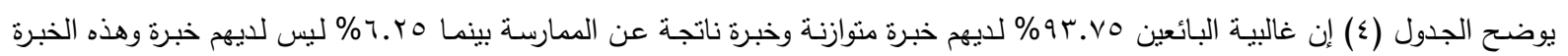
المتوفرة بين البائعين لم تأتي عن طريق دراسة متخصصي الثيء الذي يجية يجعل هذه الخبرة تتعكس سالباً علي الإنتاج والتسويق. الجدول ه: نوع التغذية.

\begin{tabular}{|c|c|c|}
\hline النسبة \% & العدد & نوع التغذية \\
\hline$T r .0$ & 1. & بذور \\
\hline $11 . V_{0}$ & $r$ & فواكه \\
\hline $1 . r 0$ & 1 & خلطات \\
\hline Ir.o & r & غذاء اخضر \\
\hline$\% 1 \ldots$ & 17 & المجموع \\
\hline
\end{tabular}

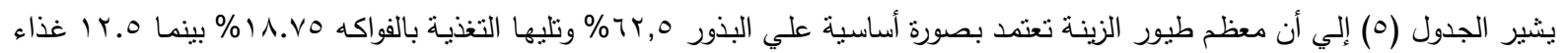

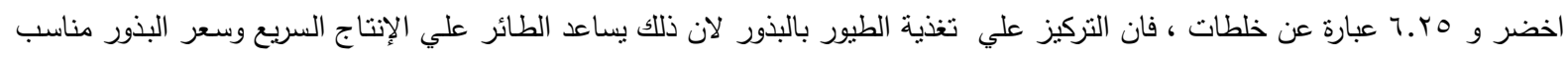

مما يحسن من تسويق طيور الزينة. الجدول 1: الإمراض التي تصيب طيور الزينة.

\begin{tabular}{|c|c|c|}
\hline النسبة \% & العدد & نوع المرض \\
\hline Tr.O & 1. & زكام \\
\hline \%ro & $\varepsilon$ & إسهال \\
\hline$\% 1 r .0$ & r & جرب \\
\hline$\% 1 \ldots$ & 17 & المجموع \\
\hline
\end{tabular}

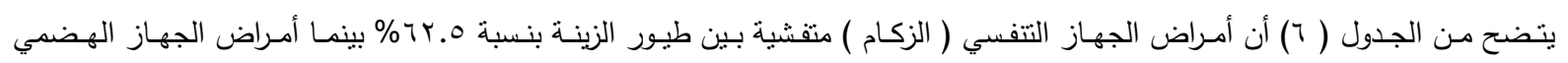

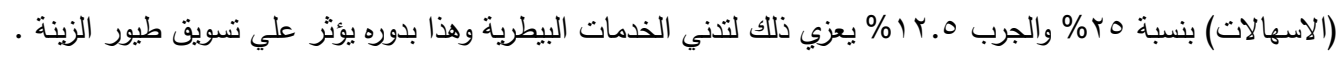


الجدول V: المدي نوفر كمية الدواء.

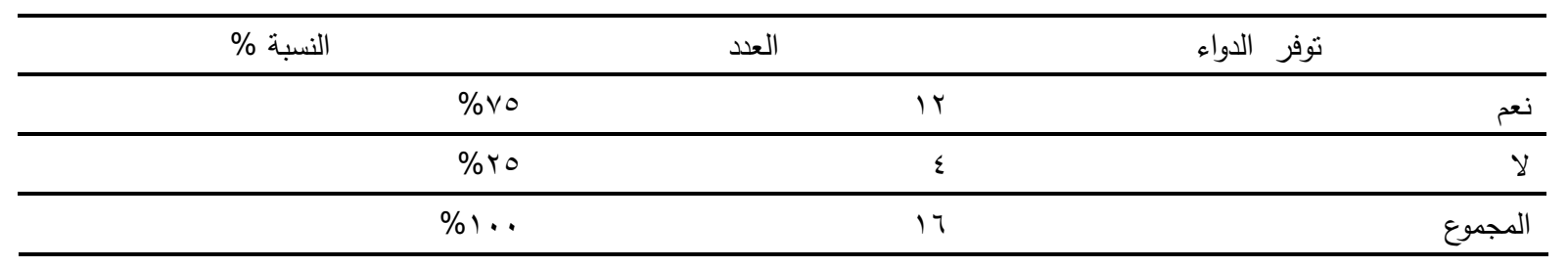

يوضح الجدول (V) إن الدواء متوفر بنسبة Vo\% الثيء الذي يجعل المربين يتمو بذلك الاستفادة منه لتقليل حد انتثار الإمراض بين القطعان .

الجدول ^^ الأسواق المتخصصة لطيور الزينة.

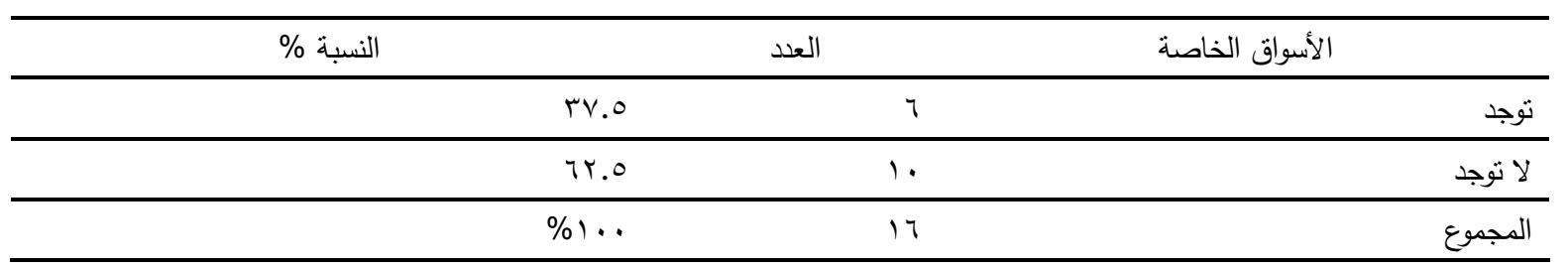

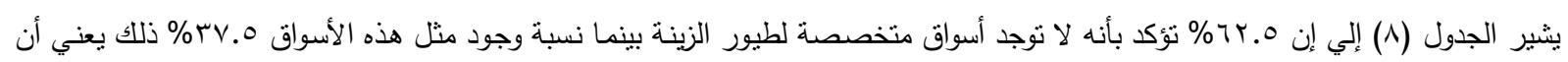
الكمية المعروضة بسيطة وغير كافية مما بسبب مشكلة في توزيع وتسويق طيور الزينة.

\section{RESULTS}

النتائـج

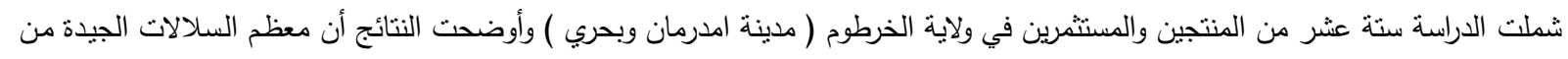

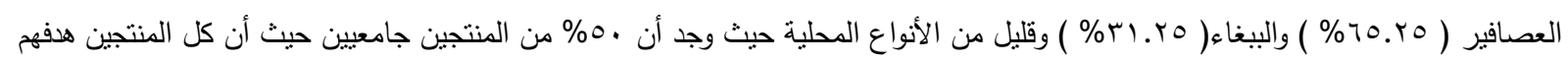

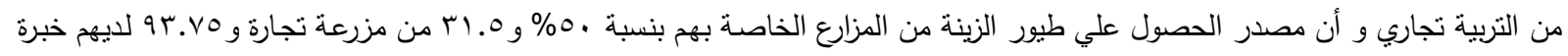

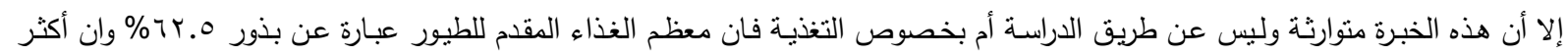

الأمراض انتشار في هذه الأسواق هي أمراض الجهاز الهضمي والتتفسي وذلك نتيجة لعدم وجود الخدمات البيطرية.

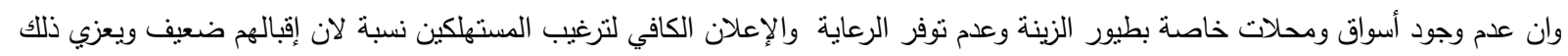

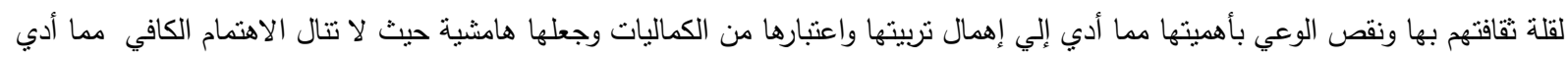

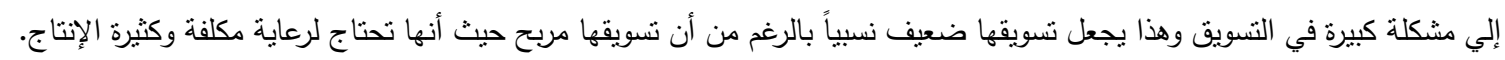

\section{PROPOSALS and Recommendations}

\section{المقترحات والتوصيات}

- - تعريف المربين بطرق ومواد التغذية المنكاملة للطيور وتوفير العلائق المنوازنة.

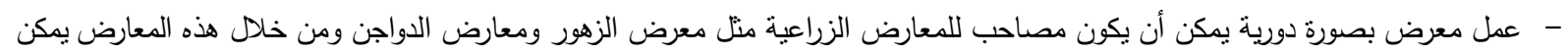
عرض طيور الزينة وتعريف الجمهور بها وعمل مسابقات تخص طيور الزينة ـ هذا يؤدي بتجويد العمل كما يربط البائع بالجمهور.

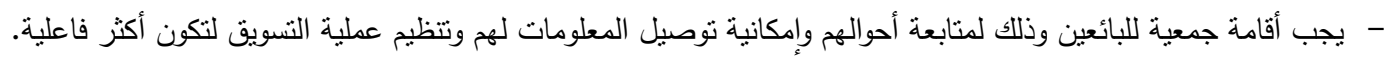
- نشر ثقافة طيور الزينة وتثقيف الجمهور لها عن طريق عمل كتيبات ومنشورات توضح أهمية تربيتها وفوائدها.

\section{REFERENCES}

المراجـ

احمد علي كامل - نربية طيور الزينة - الناشر المعارف الاسكندرية.

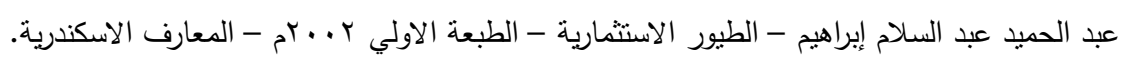
حسين عبد الحي قاعود - الحمام وطيور الزينة - .... بام - المعارف القاهرة. WWW. MMLKAT .com 